\title{
Quantitative p16 and ESR1 methylation in the peripheral blood of patients with non-small cell lung cancer
}

\author{
YASUHIRO SUGA, KUNIHARU MIYAJIMA, TAKEFUMI OIKAWA, JUNICHI MAEDA, \\ JITSUO USUDA, NAOHIRO KAJIWARA, TATSUO OHIRA, OSAMU UCHIDA, \\ MASAHIRO TSUBOI, TAKASHI HIRANO, HARUBUMI KATO and NORIHIKO IKEDA \\ Department of Thoracic Surgery, Tokyo Medical University Hospital, \\ 6-7-1, Nishishinjuku, Shinjuku-ku, Tokyo 160-0023, Japan
}

Received April 9, 2008; Accepted May 20, 2008

DOI: $10.3892 /$ or_00000121

\begin{abstract}
Inactivation of the $p 16$ and ESRI tumor suppressor genes by promoter lesion methylation has been reported in many tumor types, including lung cancer. We examined the blood of 95 non-small cell lung cancer patients (66 cases of adenocarcinoma, 23 of squamous cell carcinoma and 6 of large cell carcinoma) and 30 controls consisting of normal subjects and benign disease patients to determine the methylation ratios of $p 16$ and ESRl using real-time PCR. For both genes, there was a statistically significant difference in the methylation ratio between non-small cell lung cancer patients and controls ( $p 16 ; \mathrm{p}<0.01, E S R 1 ; \mathrm{p}<0.001)$. In addition, there was a strong correlation between the methylation ratio of each gene and old age $(p 16 ; \mathrm{p}<0.01$, ESR1; $<<0.001$ and $p 16$ or ESR1; $<<0.001$ ), and between $p 16$ or ESR 1 methylation rate and smoking history $(\mathrm{p}<0.01)$. Moreover in Stage I cases, the methylation positive rate of each gene ( $p 16, E S R 1$ and $p 16$ or ESRl) was higher than the CEA positive rate $(\mathrm{p}<0.05, \mathrm{p}<0.001, \mathrm{p}<0.001)$. Evaluation of p16 and ESR 1 promoter methylation in blood using real-time PCR appears to be very useful for lung cancer diagnosis and there is some possibility that these methylated genes might come to represent useful biomarkers for the early detection of lung cancer. Our study results also suggested that comparative evaluation of the methylation ratio before and after surgery might be a powerful tool to predict the prognosis of lung cancer patients.
\end{abstract}

\section{Introduction}

Lung cancer is the leading cause of cancer-related deaths in Japan. Lung cancer screening by chest X-ray and sputum

Correspondence to: Dr Kuniharu Miyajima, Department of Thoracic Surgery, Tokyo Medical University, 6-7-1, Nishishinjuku, Shinjuku-ku, Tokyo 160-0023, Japan

E-mail: miyajima@wb3.so-net.ne.jp

Key words: p16, ESR1, methylation, real-time PCR, non-small cell lung cancer cytology has not resulted in any improvement of the mortality rate of this cancer, either in Japan or in any other country. Therefore, it is very important to identify and develop reliable diagnostic and prognostic markers of early-stage lung cancer. We would like to suggest some new possibilities for early detection.

Previous evidence suggests that tumor cells may release DNA into the circulation, causing the serum to become enriched with the DNA (1). In lung cancer, promoter hypermethylation has been detected in blood, bronchial lavage, sputum and pleural fluid of lung cancer patients (2-5). Thus, DNA methylation in blood might represent a field defect of change. We tested $p 16$ and ESR1 (ESR 1- $\alpha)$ promoter hypermethylation in the blood by real-time PCR, which is more sensitive than methylation-specific PCR (6-8). p16 is a well-known D-type cyclin-dependent kinase (cdk) inhibitor gene that interferes with the interaction of cdk4 with cyclin $\mathrm{D}_{1}$, stimulating the progression of eukaryotic cells through the G1 phase of the cell cycle. The relation between $p 16$ methylation and lung cancer has been confirmed in tumor, tissue and serum samples (9).

ESR1 has been mapped to chromosome 6p25 and belongs to the superfamily of transcription activators $(10,11)$. ESRI has also been shown to have growth-suppressive functions ESR 1 promoter hypermethylation has been shown to be associated with irreversible inhibition of gene transcription in many cancers, including colon cancer, breast cancer, cervical cancer, and hematopoietic neoplasms (12-14). A previous study indicated that ESRI- $\alpha$ may play a more important role than $E S R I-\beta$ in lung cancer. Recently, hypermethylation of ESR 1 was reported in a lung cancer cell line as well as in lung cancer specimens $(11,15)$. Some studies showed that loss of ESR1 expression was associated with aberrant 5'CpG island hypermethylation in breast cancer, colon cancer and lung cancer $(11,12,16,17)$. Therefore, we tested $p 16$ and ESR 1 methylation in blood of lung cancer patients and patients with benign diseases.

\section{Materials and methods}

Collection samples. We examined whether aberrant p16 and ESR 1 methylation might be found in the blood of non-small cell lung cancer (NSCLC) patients by real-time PCR in 
Table I. p16, ESR1, and p16 or ESR1 methylation positive rates (\%) in normal control and benign disease patients and NSCLC patients.

\begin{tabular}{lccc}
\hline & $p 16$ & ESRI & p16 or ESRI \\
\hline Sensitivity & $26.3(25 / 95)$ & $52.6(50 / 95)$ & $62.1(59 / 95)$ \\
Specificity & $96.7(29 / 30)$ & $90.0(27 / 30)$ & $86.7(26 / 30)$ \\
Accuracy & $43.2(54 / 125)$ & $61.6(77 / 125)$ & $68.0(85 / 125)$ \\
Positive predictive value & $96.2(25 / 26)$ & $94.3(50 / 53)$ & $93.7(59 / 63)$ \\
P-value & $\mathrm{p}<0.01^{\mathrm{a}}$ & $\mathrm{p}<0.001^{\mathrm{a}}$ & $\mathrm{p}<0.001^{\mathrm{b}}$ \\
\hline
\end{tabular}

${ }^{\mathrm{a}}$ t-test, ${ }^{\mathrm{b}} \chi^{2}$ test. P-value, benign and normal control cases vs. NSCLC patients.

A

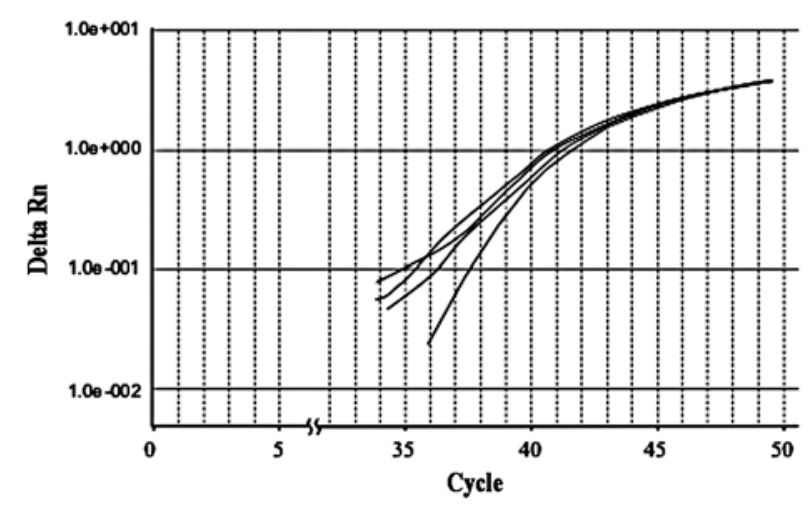

B

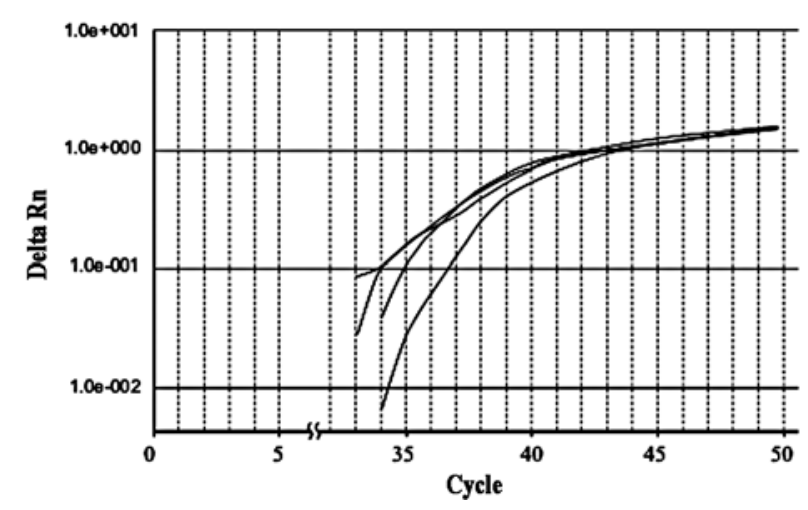

Figure 1. Amplification plots for the p16 real-time PCR analysis of blood DNA samples (A). X-axis, the cycle number of quantitative PCR; Y-axis, Delta $\mathrm{Rn}$, fluorescence intensity over the background. Amplification plots for the ESR1 real-time PCR analysis of blood DNA samples (B). X-axis, the cycle number of quantitative PCR; Y-axis, Delta Rn, fluorescence intensity over the background.

specimens obtained from healthy volunteers and benign disease patients and patients with lung cancer. With written informed consent and in accordance with the Declaration of Helsinki, peripheral blood samples were obtained from 95 patients with NCSLC, including 66 with adenocarcinoma, 23 with squamous cell carcinoma, 6 with large cell carcinoma and 30 controls consisting of normal subjects and benign disease patients. This last group of 30 samples was obtained from 16 normal controls and 14 benign disease patients, including 5 with tuberculosis, 2 with mediastinal tumors, 2 with pneumonia, and 5 with other diseases. Among lung cancer patients, there were 52 Stage I cases, 8 Stage II, 23 Stage III, and 12 Stage IV. Patients with multiple primary cancers were excluded. The diagnosis in all the patients was made by the pathologists at our hospital.

DNA extraction, bisulfite treatment and methylation-specific real-time PCR. Peripheral blood samples were collected to investigate the methylation status of blood DNA. The buffy coat was isolated after centrifugation at 3,000 rpm for $10 \mathrm{~min}$ and blood DNA was extracted using phenol/chloroform extraction from blood (EDTA-2Na). Bisulfite conversion of DNA samples was carried out as previously described (18). The bisulfited DNA, p16 and ESR1, as well as the internal reference gene MYOD1, were used as the templates for realtime PCR. The ratios between the values for the gene of interest versus the internal reference gene obtained by the TaqMan analysis were used to represent the relative level of methylated p16 and ESR1 DNA in a given sample. The sequences of the primers and probes used to amplify and detect methylated p16, ESR 1 and MYOD were as follows, and have been described previously $(19,20)$. p16: 5'-CGCAA CCGCCGAACG-3' (forward primer), 6FAM-5'-CGCGAT CCGGCCCACCCT-TAMRA-3' (probe) and 5'-TTTTTT CGTTAGTATCGGAGGAAGA-3' (reverse primer). ESRl: 5'-GGCGTTCGTTTTGGGATTG-3' (forward primer), 6FAM-5'-CGATAAAACCGAACGACCCGACGATAMRA-3' (probe) and 5'-GCCGACACGCGAACTCTAA-3' (reverse primer). MYOD: 5'-TGATTAATTTAGATTGGGT TTAGAGAAGGA-3' (forward primer), 6FAM-5'-TCC CTTCCTATTCCTAAATCCAACCTAAATACCTCC-3'TAMRA (probe) and 5'-CCAACTCCAAATCCCCTCTC TAT-3' (reverse primer).

Real-time PCR is based on continuous optical monitoring of a progressive fluorogenic PCR. We used Prism 7000 (Applied Biosystems) for this study. The methylation ratio was defined as the ratios of the fluorescence emission intensity values for the $p 16$ and ESRI PCR products to those of the MYOD1 PCR products obtained by TaqMan analysis, multiplied by 100,000 and 10,000 .

Statistical analysis. The correlation between the methylation ratios p16 and ESR1 was evaluated by $\chi^{2}$ test and Welch's 
Table II. p16, ESRI, and p16 or ESRI methylation positive rates (\%) classified according to the gender, age, smoking history, histological type and clinical stage.

\begin{tabular}{|c|c|c|c|}
\hline & pl6 & ESRl & p16 or ESR1 \\
\hline \multicolumn{4}{|l|}{ Gender } \\
\hline Male & $23.2(19 / 82)$ & $40.2(33 / 82)$ & $51.2(42 / 82)$ \\
\hline Female & $16.3(7 / 43)$ & $46.5(20 / 43)$ & $46.5(21 / 43)$ \\
\hline \multicolumn{4}{|l|}{ Age (years) } \\
\hline$<63$ & $9.1(5 / 55)^{\mathrm{a}}$ & $31.0(17 / 55)^{\mathrm{c}}$ & $34.5(19 / 55)^{\mathrm{c}}$ \\
\hline$\geq 63$ & $30.0(21 / 70)$ & $51.4(36 / 70)$ & $62.9(44 / 70)$ \\
\hline \multicolumn{4}{|l|}{ Smoking history } \\
\hline Non-smoker & $16.2(12 / 74)$ & $36.5(27 / 74)$ & $40.5(30 / 74)^{b}$ \\
\hline Smoker & $27.5(14 / 51)$ & $51.0(26 / 51)$ & $65.0(33 / 51)$ \\
\hline \multicolumn{4}{|l|}{ Histological type } \\
\hline $\mathrm{ADC}$ & $21.2(14 / 66)$ & $53.0(35 / 66)$ & $60.6(40 / 66)$ \\
\hline SCC & $39.1(9 / 23)$ & $47.8(11 / 23)$ & $65.2(15 / 23)$ \\
\hline LCC & $33.3(2 / 6)$ & $50.0(3 / 6)$ & $66.7(4 / 6)$ \\
\hline \multicolumn{4}{|l|}{ Clinical stage } \\
\hline I & $21.2(11 / 52)$ & $55.8(29 / 52)$ & $61.5(32 / 52)$ \\
\hline II & $37.5(3 / 8)$ & $25.0(2 / 8)$ & $50.0(4 / 8)$ \\
\hline III & $26.1(6 / 23)$ & $43.5(10 / 23)$ & $56.5(13 / 23)$ \\
\hline IV & $41.6(5 / 12)$ & $66.6(8 / 12)$ & $83.3(10 / 12)$ \\
\hline
\end{tabular}

${ }^{\mathrm{a}} \mathrm{p}<0.05,{ }^{\mathrm{b}} \mathrm{p}<0.01,{ }^{\mathrm{c}} \mathrm{p}<0.001, \chi^{2}$ test. ADC; adenocarcinoma, SCC; squamous cell carcinoma, LCC; large cell carcinoma

t-test using the SPSS. The relationship between $p 16$ and ESR 1 promoter methylation in blood and the clinicopathological characteristics of the patients was assessed by $\chi^{2}$ test and Welch's t-test using the same software. Statistical significance was assumed to be indicated by $\mathrm{p}<0.05$.

\section{Results}

p16 methylation in blood of controls and NSCLC patients. p16 methylation ratios in controls and NSCLC patients are shown. The ratios were corrected by the value for the internal reference gene MYOD1. p16 median methylation level in the controls was $1.3 \pm 0.9$ (mean $\pm \mathrm{SE})$, while that in the NSCLC patients was $18.6 \pm 5.1$ (Fig. 1A). The difference in the ratios between the NSCLC patients and controls consisting of normal subjects and benign disease patients was statistically significant $(\mathrm{p}<0.01)$. We determined the cutoff value as 3.0 , and based on this cutoff value, the sensitivity of the determination for the diagnosis of lung cancer was $26.3 \%$, specificity was $96.7 \%$, accuracy was $43.2 \%$ and positive predictive value was $96.2 \%$ (Table I).

ESR1 methylation in blood of controls and NSCLC patients. The ESRI median methylation level in controls was 1.2 \pm 0.6 (mean $\pm \mathrm{SE}$ ), while that in the NSCLC patients was 9.0 \pm 2.0 (Fig. 1B). The difference between the values in the NSCLC controls was statistically significant $(p<0.001)$. We determined the cutoff line as 2.5 , and based on this cutoff value, the sensitivity of the determination for the diagnosis of lung cancer was $52.6 \%$, specificity was $90.0 \%$, accuracy was $61.6 \%$ and positive predictive value was $94.3 \%$ (Table I).

Associations with clinicopathological variables of the methylation positive rates of p16 and ESR1. We analyzed the correlations between the DNA methylation positive rates of DNA in blood and various clinicopathological variables. There was a strong statistically significant difference between $p 16$ and ESR 1 methylation positive rates in patients $<63$ years old and those $\geq 63$ years old $(\mathrm{p}<0.01, \mathrm{p}<0.001)$. However, there were no statistically significant correlations between the methylation rates of p16 and ESRI and gender, smoking history, histological type or clinical stage (Table II).

p16 or ESR1 methylation positive rates in the blood of controls and NSCLC patients. There were statistically significant differences in the methylation positive rates of $p 16$ or ESRI between the NSCLC patients and controls $(\mathrm{p}<0.001)$. The sensitivity of p16 or ESR1 methylation positive rates for the diagnosis of lung cancer was $62.1 \%$, specificity was $86.7 \%$, accuracy was $68.0 \%$, and positive predictive value was $93.7 \%$ (Table I). In addition, we found significant correlation between p16 or ESR1 methylation rates and old age $(\mathrm{p}<0.001)$, smoking history $(\mathrm{p}<0.01)$ (Table II).

Comparison between the methylation positive rates and tumor marker positive rates. In this study, the methylation positive 
Table III. Comparison of p16, ESR1, and p16 or ESR1 methylation positive rates (\%) and positive rates (\%) of tumor markers in each clinical stage.

\begin{tabular}{lcccc}
\hline Stage & I & II & III & IV \\
\hline pl6 & $21.2^{\mathrm{a}}$ & 37.5 & 26.1 & 41.6 \\
ESR1 & $55.8^{\mathrm{b}}$ & 25.0 & 43.5 & 66.6 \\
p16 or ESR1 & $61.5^{\mathrm{b}}$ & 50.0 & $56.5^{\mathrm{c}}$ & 83.3 \\
CEA & 5.8 & 25.0 & 17.4 & 41.6 \\
Tumor markers & 19.2 & 50.0 & 47.8 & 50.0 \\
\hline
\end{tabular}

Tumor markers, at least one serum protein marker (CEA, CA19-9, SLX, SCC and CYFRA). ${ }^{a}$ vs. CEA: $p<0.05,{ }^{b}$ vs. CEA or tumor makers: $\mathrm{p}<0.001,{ }^{\mathrm{c}} \mathrm{vs}$. CEA: $\mathrm{p}<0.03$.

rates of $p 16, E S R 1$, and $p 16$ or ESR1 were compared with the positive rates of the serum protein tumor makers. The most commonly evaluated tumor markers in the clinical situation are CEA (carcinoembryonic antigen), CA19-9 (carbohydrate antigen 19-9), SLX (Sialyl Lewisx-i antigen), SCC (squamous cell carcinoma antigen) and CYFRA (cytokeratin 19 fragment). We investigated the correlations between the clinical stage and the methylation positive rates of the two genes (p16, ESR1, and $p 16$ or ESRI) and of the serum protein tumor markers.

Since CEA is the most commonly evaluated serum protein tumor marker in patients of NSCLC, we examined the methylation positive rates of each of the genes in blood and of the CEA positive rate. In cases with Stage I lung cancer, there was a statistically significant difference in the methylation positive rate of each gene ( $p 16, E S R 1$, and $p 16$ or ESR 1$)$ and the CEA positive rate $(\mathrm{p}<0.05, \mathrm{p}<0.001$, $\mathrm{p}<0.001)$. In cases with Stage III also, a statistically significant difference was detected between the CEA positive rate and p16 or ESR1 methylation positive rate $(\mathrm{p}<0.03)$ Furthermore, in Stage I cases, there were statistically significant differences between at least one of the serum protein tumor markers and ESRI and p16 or ESR1 positive rates $(\mathrm{p}<0.001, \mathrm{p}<0.001)$ (Table III).

\section{Discussion}

Previous studies have shown that aberrant promoter hypermethylation can be detected in specimens obtained from patients with no evidence of histopathological malignancy. In lung cancer patients, promoter hypermethylation has been detected in blood, bronchial lavage, sputum and pleural fluid of lung cancer patients (2-5). These aberrant hypermethylations have also been reported to be present in the primary tumor and thus may represent a field defect of changes that occur early in tumorigenesis, just like the presence of microsatellite instability in the majority of colorectal carcinomas $(21,22)$.

Malignant associated changes have been reported as subtle morphological changes in the nuclei of normal cells found in the vicinity of the malignant growth. We regard this as one type of field cancerization (23). We used peripheral blood as the specimens in this study. In a previous study in which peripheral blood buffy coat specimens were used as the specimens to evaluate $p 16$ methylation status in cases of hepatocellular carcinoma, the median p16 methylation ratio in the postoperative buffy coat specimens was significantly lower than that in the preoperative samples. The tendency of the methylation ratio to decline was shown to be greater in the buffy coat than in plasma specimens (8). It has been suggested that the degree of apoptosis and necrosis might affect the amount of tumor DNA released into the bloodstream. Thus, we believe that circulation DNA might be present in peripheral blood of cancer patients and represent a field defect of preneoplastic change.

This study showed the possibility of methylated DNA evaluated in peripheral blood samples becoming a useful biomarker for detection of lung cancer. There was a statistically significant difference in p16 and ESR 1 methylation ratios between NSCLC patients and controls $(\mathrm{p}<0.01, \mathrm{p}<0.001)$. We found that the sensitivity and specificity improved with evaluation of a combination of the two genes (Table I), and that the test may be potentially useful for mass screening of lung cancer and follow-up of lung cancer patients (24). The main factors influencing the ratio of DNA methylation in lung cancer patients have been shown to be the presence of malignant disease, including that of double cancer, old age and smoking history. Our results demonstrated the strong statistically significant differences of p16, ESR1, and p16 or ESR1 promoter methylation positive rates between patients aged $<63$ years and those aged $\geq 63$ years $(\mathrm{p}<0.01, \mathrm{p}<0.001, \mathrm{p}<0.001)$. The finding of a significant difference in p16 or ESR1 methylation positive rate between smokers and non-smokers is also of interest $(\mathrm{p}<0.01)$. Previous studies have shown old age and smoking as being strong risk factors for lung cancer and also as bearing strong correlations with the DNA methylation change. $(12,25,26)$ DNA methylation was detected in lung cancer patients of all stages in this study.

Comparison of the DNA methylation positive rates with the CEA positive rate in Stage I cases showed that the DNA methylation positive rates of the genes (p16, ESR1, p16 or ESR I) were higher than the positive rates of CEA or any other tumor markers. Therefore, there is some possibility that evaluation of DNA methylation might become a more powerful tool in the early detection of lung cancer and lung cancer screening than the evaluation of tumor makers. There was only one false-positive case of p16 methylation in our study; this case, who was diagnosed to have tuberculosis, was a 78-year-old man who was a heavy smoker (58 packyears: p.y.). On the other hand, there were 3 false-positive cases of ESRI methylation. One of the cases had pneumonia, and the patient was an extraordinarily heavy smoker ( 92.5 p.y.). In the second case, the serum level of the tumor maker CYFRA was increased in the absence of any cancer. The third false-positive case was diagnosed to have emphysema and was an 80-year-old man who was a heavy smoker (60 p.y.). Old age and smoking have been reported as strong risk factors for lung cancer and to bear strong correlations with the DNA methylation change $(25,26)$. Based on our results, we believe that old age is an especially strong risk factor for p16 methylation, and the association warrants a careful investigation to determine if cases showing $p 16$ methylation are likely to be found to have malignancy in the near future. 
We examined p16 and ESRI methylation ratios in 26 lung cancer patients before and after curative surgery. The mean period from post operation to obtaining blood samples was $11.9 \pm 9.0$ months. In relation to $p 16$ methylation, 19 cases were negative both before and after the operation. In 4 cases, methylation ratios increased after the operation and in 3 cases, it decreased. Two of the four cases in which it increased, including one with p-Stage IA, were diagnosed to have recurrence. The other $\mathrm{p}$-Stage IA case had prostate cancer after curative surgery. The median postoperative methylation level in cases with recurrence or double cancer was shown to be 17.6-fold higher than the overall median preoperative methylation level. On the other hand, in cases without recurrence, the median postoperative methylation level was about one-third lower than the median preoperative methylation level. In relation to ESR 1 the methylation ratios were increased in 7 cases and decreased in 9 cases after curative surgery. Of the 7 cases in which it was increased, including 2 cases with p-Stage I, 4 were diagnosed to have recurrence, whereas no evidence of recurrence was found in the remaining 3 cases. We propose to carefully follow up these latter 3 cases to detect possible recurrence. Thus, quantitative analysis of the methylation ratio may allow follow-up of longitudinal changes of the methylation ratios in lung cancer patients (27).

In clinical situations, adjuvant chemotherapy has been established by consensus as efficient standard therapy. Evaluation of the methylation ratio before and after surgery may be useful to determine whether or not adjuvant chemotherapy must be administered. We consider that methylationpositive patients after curative surgery should receive adjuvant chemotherapy $(28,29)$.

In conclusion, detection of aberrant p16 and ESR 1 promoter methylation in blood samples using real-time PCR appears to be useful in the diagnosis of lung cancer, early lung cancer detection and also clinical follow-up of lung cancer patients.

\section{Acknowledgements}

This study was supported by a Grant-in-Aid for scientific research from the Ministry of Education, Culture, Sports, Science and Technology KAKENHI (17591488).

\section{References}

1. An Q, Liu Y, Gao Y, Huang J, Fong X, Li L, Zhang D and Cheng S: Detection of $p 16$ hypermethylation in circulating plasma DNA of non-small cell lung cancer patients. Cancer Lett 188: 109-114, 2002.

2. Esteller M, Sanchez-Cespedes M, Rosell, Sidransky D, Baylin SB and Herman JG: Detection of aberrant promoter hypermethylation of tumor suppressor genes in serum DNA from non-small cell lung cancer patients. Cancer Res 59: 67-70, 1999.

3. Ahrendt SA, Chow JT, Xu LH, Yang SC, Eisenberger CF, Esteller M, Herman JG, Wu L, Decker PA, Jen J and Sidransky D: Molecular detection of tumor cells in bronchoalveolar lavage fluid from patients with early stage lung cancer. J Natl Cancer Inst 91: 332-339, 1999.

4. Belinsky SA, Palmisano WA, Gilliland FD, Crooks LA, Divine KK, Winters SA, Grimes MJ, Harms HJ, Tellez CS, Smith TM, Moots PP, Lechner JF, Stidley CA and Crowell RE: Aberrant promoter methylation in bronchial epithelium and sputum from current and former smokers. Cancer Res 62: 2370-2377, 2002.
5. Ng CS, Zhang J, Wan S, Lee TW, Arifi AA, Mok T, Lo DY and Yim AP: Tumor $p 16 \mathrm{M}$ is a possible marker of advanced stage in non-small cell lung cancer. J Surg Oncol 79: 101-106, 2002.

6. Brabender J, Usadel H, Danenberg KD, Metzger R, Schneider PM, Lord RV, Wickramasinghe K, Lum CE, Park J, Salonga D, Singer J, Sidransky D, Holscher AH, Meltzer SJ and Danenberg PV: Adenomatous polyposis coli gene promoter hypermethylation in non-small cell lung cancer is associated with survival. Oncogene 20: 3528-3532, 2001.

7. Hoque MO, Begum S, Topaloglu O, Jeronimo C, Mambo E, Westra WH, Califano JA and Sidransky D: Quantitative detection of promoter hypermethylation of multiple genes in the tumor, urine, and serum DNA of patients with renal cancer. Cancer Res 64: 5511-5517, 2004.

8. Wong IH, Zhang J, Lai PB, Lau WY and Lo YM: Quantitative analysis of tumor-derived methylated p16INK4a sequences in plasma, serum, and blood cells of hepatocellular carcinoma patients. Clin Cancer Res 9: 1047-1052, 2003.

9. Belinsky SA, Nikula KJ, Palmisano WA, Michels R, Saccomanno G, Gabrielson E, Baylin SB and Herman JG: Aberrant methylation of p16(INK4a) is an early event in lung cancer and a potential biomarker for early diagnosis. Proc Natl Acad Sci USA 95: 11891-11896, 1998.

10. Issa JP, Zehnbauer BA, Civin CI, Collector MI, Sharkis SJ, Davidson NE, Kaufmann SH and Baylin SB: The estrogen receptor $\mathrm{CpG}$ island is methylated in most hematopoietic neoplasms. Cancer Res 53: 973-977, 1996.

11. Lai JC, Cheng YW, Chiou HL, Wu MF, Chen CY and Lee H: Gender difference in estrogen receptor alpha promoter hypermethylation and its prognostic value in non-small cell lung cancer. Int J Cancer 117: 974-980, 2005.

12. Issa JP, Ottaviano YL, Celano P, Hamilton SR, Davidson NE and Baylin SB: Methylation of the oestrogen receptor $\mathrm{CpG}$ island links ageing and neoplasia in human colon. Nat Genet 7: 536-540, 1994.

13. Zajchowski DA, Sager R and Webster L: Estrogen inhibits the growth of estrogen receptor-negative, but not estrogen receptorpositive, human mammary epithelial cells expressing a recombinant estrogen receptor. Cancer Res 53: 5004-5011, 1993.

14. Issa JP, Baylin SB and Belinsky SA: Methylation of the estrogen receptor $\mathrm{CpG}$ island in lung tumors is related to the specific type of carcinogen exposure. Cancer Res 56: 3655-3658, 1996.

15. Marchevsky AM, Tsou JA and Laird-Offringa IA: Classification of individual lung cancer cell lines based on DNA methylation markers: use of linear discriminant analysis and artificial neural networks. J Mol Diagn 6: 28-36, 2004.

16. Lapidus, RG, Ferguson AT, Ottaviano YL, Parl FF, Smith HS, Weitzman SA, Baylin SB, Issa JP and Davidson NE: Methylation of estrogen and progesterone receptor gene 5' $\mathrm{CpG}$ islands correlates with lack of estrogen and progesterone receptor gene expression in breast tumors. Clin Cancer Res 2: 805-810, 1996.

17. Ottaviano YL, Issa JP, Parl FF, Smith HS, Baylin SB and Davidson NE: Methylation of the estrogen receptor gene $\mathrm{CpG}$ island marks loss of estrogen receptor expression in human breast cancer cells. Cancer Res 54: 2552-2555, 1994.

18. Herman JG, Graff JR, Myohanen S, Hamilton SR, Nelkin BD and Baylin SB: Methylation-specific PCR. A novel PCR assay for methylation status of $\mathrm{CpG}$ islands. Proc Natl Acad Sci USA 93: 9821-9826, 1996.

19. Eads CA, Lord RV, Wickramasinghe K, Long TI, Kurumboor SK, Bernstein L, Peters JH, DeMeester SR, DeMeester TR, Skinner KA and Laird PW: Epigenetic patterns in the progression of esophageal adenocarcinoma. Cancer Res 61: 3410-3418, 2001 .

20. Toyooka KO, Toyooka S, Maitra A, Feng Q, Kiviat NC, Smith A, Minna JD, Ashfaq R and Gazdar AF: Establishment and validation of real-time polymerase chain reaction method for CDH1 promoter methylation. Am J Pathol 161: 629-634, 2002.

21. Guo M, House MG, Hooker C, Han Y, Heath E, Gabrielson E, Yang SC, Baylin SB, Herman JG and Brock MV: Promoter hypermethylation of resected bronchial margins: a field defect of changes? Clin Cancer Res 10: 5131-5136, 2004.

22. Jones PA and Laird PW: Cancer epigenetics comes of age. Nat Genet 21: 163-167, 1999.

23. Ikeda N, MacAulay C, Lam S, LeRiche J, Payne P, Garner D, Konaka C, Kato $\mathrm{H}$ and Palcic B: Malignancy associated changes in bronchial epithelial cells and clinical application as a biomarker. Lung Cancer 19: 161-166, 1998. 
24. Ulivi P, Zoli W, Calistri D, Fabbri F, Tesei A, Rosetti M, Mengozzi $M$ and Amadori D: p16INK4A and CDH13 hypermethylation in tumor and serum of non-small cell lung cancer patients. J Cell Physiol 206: 611-615, 2006.

25. Issa JP, Vertino PM, Boehm CD, Newsham IF and Baylin SB: Switch from monoallelic to biallelic human IGF2 promoter methylation during aging and carcinogenesis. Proc Natl Acad Sci USA 93: 11757-11762, 1996.

26. Guo M, Akiyama Y, House MG, Hooker CM, Heath E, Gabrielson E, Yang SC, Han Y, Baylin SB, Herman JG and Brock MV: Hypermethylation of the GATA genes in lung cancer. Clin Cancer Res 10: 7917-7924, 2004.
27. Shao ZM and Guyen MN: Tumor-specific DNA in plasma of breast cancer patients. Anticancer Drugs 13: 353-357, 2002.

28. Kato H, Ichinose Y, Ohta M, Hata E, Tsubota N, Tada H, Watanabe Y, Wada H, Tsuboi $\mathrm{M}$ and Hamajima N: A randomized trial of adjuvant chemotherapy with uracil-tegafur for adenocarcinoma of the lung. N Engl J Med 350: 1713-1721, 2004.

29. Arriagada R, Bergman B, Dunant A, Le Chevalier T, Pignon JP and Vansteenkiste J: Cisplatin-based adjuvant chemotherapy in patients with completely resected non-small-cell lung cancer. $\mathrm{N}$ Engl J Med 350: 351-360, 2004. 